\title{
La séptima función del lenguaje
}

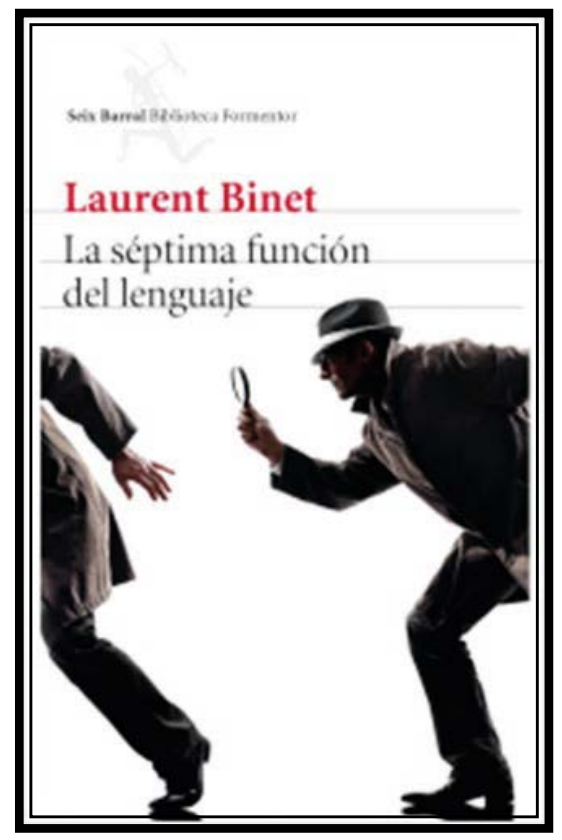

Laurent Binet. (2015). La séptima función del lenguaje. Bogotá: Editorial Planeta Colombia.

Lo que se presentará como reseña no es más que una nota de prensa ${ }^{1}$ que anuncia esta obra y cuyo autor no sería exclusivamente periodista; sería alguien -posiblemente un invitado- que construye un sencillo resumen a medida que pica la obra y sin el sustento de la teoría semiótica. Es alguien capaz de hacer reseñas sin llegar a leer el libro (cómo hablar de un libro sin leerlo).

En La séptima función del lenguaje, Binet toma como punto de partida la tarde del 25 de febrero de 1980 en que el crítico y teórico Roland Barthes, tras almorzar con el líder socialista François Mitterrand, es atropellado por una camioneta cuando cruzaba la rue des Écoles en dirección al Collège de France. El accidente no resulta fatal, pero aun así Barthes morirá, luego de pasar un mes internado en el hospital de la Pitié-Salpêtrière, víctima de complicaciones pulmonares.

Sin embargo, y he aquí el gancho de esta novela, Binet introduce desde el vamos la hipótesis de que, a Barthes, en realidad, lo asesinaron. No es ésta, hay que decir, la primera vez que Barthes aparece como personaje en una novela ni será, vale aventurar, la última. Pero ahora vienen al caso dos de ellas: Mujeres (1983), de Phillipe Sollers, y Los samuráis (1990), de Julia Kristeva. Aunque fraseológicamente muy diferentes, estas novelas comparten, la una con la otra, un sesgo autobiográfico y crepuscular, y con La séptima función del lenguaje, un elenco conformado por la crema del estructuralismo y posestructuralismo, por los agitadores de la señera revista Tel Quel, por los representantes de lo que las universidades norteamericanas denominaron French Theory. Aparecen Jacques Lacan, Michel Foucault, Louis Althusser, Jacques Derrida, Gilles Deleuze y Tzvetan Todorov, entre muchos otros, y Binet, claro, no pierde oportunidad aquí de convertir también en personajes centrales a Sollers y a Kristeva.

Cualquiera de los mencionados es sospechoso, en este policial con pretensiones semiológicas, de haber participado en la muerte de Barthes. Pero ¿por qué querrían asesinar al autor de

1 http://www.lanacion.com.ar/1998038-resena-la-septima-funcion-del-lenguaje-de-laurent-binnet 
Fragmentos de un discurso amoroso? Para robarle un manuscrito de dos carillas en el que se formula la "séptima función del lenguaje", una función de carácter performativo, que "permite a quien la domina convencer a cualquiera de cualquier cosa en cualquier circunstancia". Tal función se suma, pues, a las seis funciones del lenguaje registradas por el lingüista Roman Jakobson. La motivación para quedarse con ese manuscrito es, tanto por parte de los políticos como de los intelectuales, obvia: la obtención de poder. Bien puede tratarse del sillón presidencial de Francia, bien de adueñarse del máximo título del Logos Club, asociación semisecreta en la que se dan cita intelectuales y políticos para enfrentarse en duelos retóricos.

Como todo relato policial, La séptima función del lenguaje también tiene sus investigadores. Suerte de Sherlock Holmes y Dr. Watson algo desangelados, aquí la dupla la conforman Jacques Bayard, un cerril comisario de policía que combatió en la guerra de Argelia, y Simon Herzog, un progresista profesor universitario con conocimientos en semiología. El itinerario investigativo los lleva a sitios variopintos: un sauna gay frecuentado por Foucault, la Drogheria Calzolari de Bolonia donde se encuentran con Umberto Eco, la Cornell University de Nueva York, en la que se celebra un congreso sobre el giro lingüístico.

Aunque no le falta ritmo narrativo ni ingenio argumental, La séptima función del lenguaje al cabo resulta fallida: tiene sabor a intento de ajuste de cuentas con la French Theory (megalómanos e impostores, según el canchero narrador autoconsciente del libro), pero sus dardos se pierden lejos del blanco y la recreación del discurso de los personajes retratados -que ocupa buena parte del volumen- es generosa en clichés. En cierto pasaje, el narrador hace un alegato a favor del "rigor y la humildad" que caracterizan a Umberto Eco. Curiosamente, él carece de ambas cosas. Hasta aquí la nota de prensa.

¿A quién va dirigido el libro?

Va dirigido a todos aquellos que ignoran el campo de la semiótica. Es una provocación

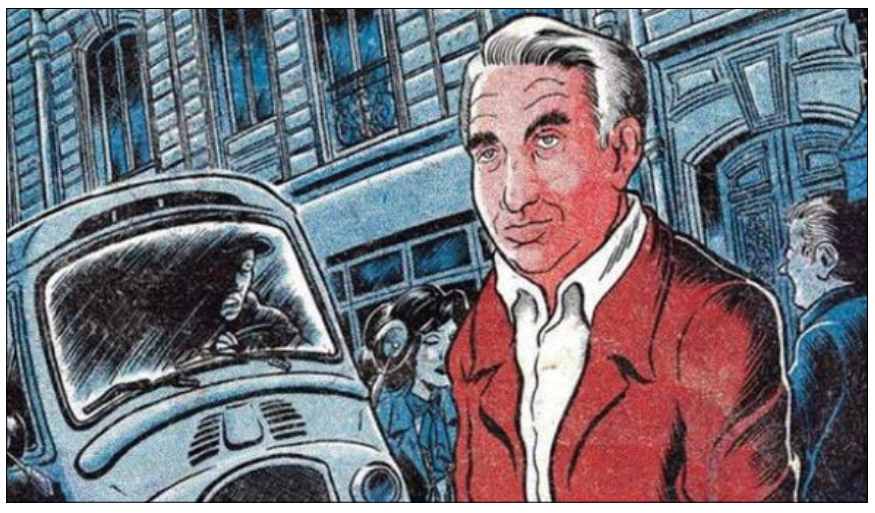

en contra del rigor y de la semiosis. Es uno de los libros que podemos entregarles, sin saber si se van a embrutecer o alienar, a estudiantes de lingüística, estudios literarios, licenciaturas en educación y hasta filosofía, deseosos de ver cómo se puede banalizar el sentido, cómo ridiculizar y distorsionar a las figuras y modelos semióticos que el autor novelista no sabía cómo interpretar. Sin embargo, el efecto banalizador del libro puede provocar algo bueno: que se trate de descubrir, desde el balcón del género literario, qué es la semiótica y quiénes han sido sus verdaderos cultivadores (no precisamente la búlgara Kristeva que merecería ser estrangulada por un estudioso y seguidor de Althusser).

Una posible lectura semiótica de la 'Séptima función del lenguaje' podría llevarnos a activar en nuestra mente una reflexión semiótica de corte althusseriano y antifilosófica: Pour ne pas se méprendre sur le sens de cette condamnation des professeurs de sémiotique, et de la sémiotique qu'ils professent, il faut prendre garde à la date du texte et à quelques expressions. Klinkenberg, reprenant Eco, condamne les professeurs de sémiotique dans leur masse, et non tous les professeurs de sémiotique sans exception. Il condamne leur sémiotique mais ne condamne pas la sémiotique.

Si esto se logra (y solo es posible en un ámbito universitario "ideal como Vincennes", no como la Jorge Tadeo o la UIS) habría que cortarle la mano al iconoclasta Binet para que emule a su personaje soñado: Simon Herzog.

Se necesita ser un Bayard para leer esa novela...

\section{Giambattista Bodoni}

